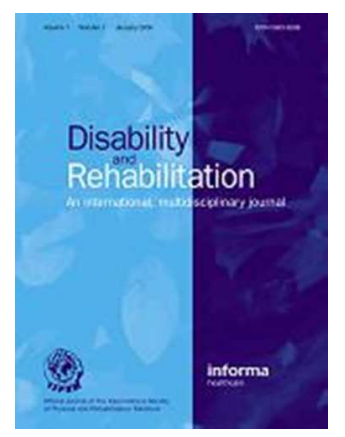

\title{
'No policy is an island': How the ICF international classification system may support local education planning in England
}

\begin{tabular}{|r|l|}
\hline Journal: & Disability and Rehabilitation \\
\hline Manuscript ID & TIDS-03-2018-029.R1 \\
\hline Manuscript Type: & Research Paper \\
\hline Keywords: & $\begin{array}{l}\text { special educational needs (SEND), SEND policy, ICF, Education, Health and } \\
\text { Care (EHC) plans, disability, SMART }\end{array}$ \\
\hline
\end{tabular}

\section{SCHOLARONE \\ Manuscripts}




\section{Implications for rehabilitation}

- The ICF can be regarded as a useful framework for supporting professionals developing targets for children with Education Health and Care (EHC) plans in England.

- $\quad$ For developing SMART targets with the ICF, professionals can use the taxonomy to look for detailed aspects of functioning, relevant to a certain developmental stage.

- $\quad$ Using the ICF can support in making more measurable targets in EHC plans if the universal qualifier scale is applied when describing detailed aspects of functioning.

- $\quad$ Professionals trained on the ICF recognise its usefulness for writing EHC targets;

- More in-depth training is recommended for supporting the development of more holistic biopsychosocial EHC plans in England. 
'No policy is an island': How the ICF international classification system may support local education planning in England

\begin{abstract}
Background: A crucial issue in special educational needs and disability policy and provision is the documentation of children's functioning, for which many countries have a statutory document. In England this is the Education Health and Care plan. Recent research challenges the quality of these plans.

Purpose: To provide evidence on the usefulness of the International Classification of Functioning, Disability and Health as a system with potential to support the development of higher quality plans in England.

Methods: Twenty-five professionals participated in a one-day training session on the International Classification of Functioning Disability and Health, with a focus on designing higher quality SMART targets to be included in children's plans.

Results: Overall, participants regarded the system as useful. Comparison of targets written before and after the training show improvements in relevance, specificity and on the extent to which they were action-oriented and measurable.

Conclusion: Results are discussed in light of international lessons learned around the potential of the International Classification of Functioning Disability and Health to support policy change. A 'no policy is an island' approach is proposed, suggesting local policymakers should open horizons beyond geographical boundaries in evidence-based decisionmaking for supporting children with disabilities.


Keywords: special educational needs (SEND); SEND policy; ICF; Education, Health and Care (EHC) plans; disability; SMART

\section{Introduction}

One of the most important aspects of service provision for children with special educational needs and disabilities is the statutory documentation describing in detail their functioning and behaviour - strengths, needs and goals for the long-term and short-term future. These documents exist in many countries with a policy for special education provision and they take a variety of names, illustrating slightly different purposes; we see Individualised Education Plans, for example, in the United States of America, which coined the term, but also in New Zealand and in most European countries; according to the European Agency for Development in Special Needs Education, at least Finland, Switzerland, Czech Republic, Sweden, Netherlands, Austria, Belgium, and Malta have IEPs [1, 2]; we also see habilitation plans in Sweden [3] and, more recently, we see Education, Health and Care plans in England [4]. The $\underline{\text { Education Health and Care plan is the current statutory document for children with special }}$ $\underline{\text { needs and disabilities in England, although it co-exists with the Individualised Education }}$ Plan. The latter is still used by some schools as a tool to record strategies employed to help children progress if they are under special education needs and disability support services. However, it does not have a statutory nature; children with Individualised Education Plans might not necessarily have an Education Health and Care plan, which has been the statutory document since 2014, with the introduction of the Children and Families Act.

Despite subtle differences which might be context- and policy-specific, all these documents have in common the fact that they should provide a clear picture of each child's functioning; however, there seems to be no consensus on whether their purpose is to provide evidence to inform service provision, or whether they serve the purpose of legal protection and 
compliance with regulatory processes, with different countries adopting different positions in this respect [1]. In England, it has been pointed out that Individualised Education Plans have been serving the purpose of ensuring accountability within the field of special needs education and the targets that they included were less for the children and professionals than they were for measuring the performance of special education as a system [5]. However, with the recent introduction of Education Health and Care plans, there is a clear shift in policy from producing mere accountability documents towards producing documents that inform service providers. An explicit requirement in the new SEND Code of Practice (2014) is that children's targets are SMART: the acronym for Specific [6, 7], Measurable [8], Actionoriented [9], Relevant [6, 7] and Time-framed [8]. It is important to highlight that the term 'targets' has a few synonyms in the international literature on special needs and disability, with other terms such as 'goals' and 'outcomes' used just as often, e.g. [10, 11]. In this paper we will consistently adopt the term 'target' to describe the objectives written for children with disabilities, specifying skills and behaviours that are set for them to achieve in a certain period of time and with the support of special education and disability support professionals. Recent research has provided evidence on the various challenges faced by_professionals in England regarding the implementation of the Education Health and Care plans, triggering the debate around the quality of those plans [12-14]. Similarly, more general challenges surrounding the new policy for SEND in England have been systematically analysed and all seem to stem from a gap between ideology and implementation; the idea behind the Education Health and Care plans is consensually well accepted, but the way that they have been implemented lacks evidence-based guidance $[12,14]$. The International Classification of Functioning, Disability and Health $[15,16]$ has been highlighted as a framework with the potential to help overcome these issues, based on evidence available from research in other countries $[12,17]$. 
In this paper we will argue for a 'no policy is an island' approach, by which evidence-based internationally-recognised models should be considered for local policy and provision in special educational needs and rehabilitation, on the condition that evidence is made available that they support higher quality documentation of children's needs and targets. We argue that local policy makers in England should open horizons beyond the borders of 'the island' and welcome international lessons learned about how to develop higher quality statutory documents for children with disabilities. Building upon the international body of research on the usefulness of the International Classification of Functioning Disability and Health for special education and disability provision, to our knowledge, this study is the first to provide evidence that the adoption of the ICF in England would be welcomed by special education $\underline{\text { and rehabilitation professionals and has the potential to help them develop SMART outcomes }}$ in the Education Health and Care plans; This evidence is provided by means of analysing the targets written for children with disabilities in their plans; targets were analysed before and after a training session on the International Classification of Functioning Disability and

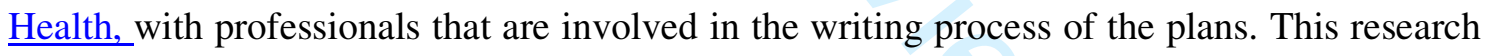
is informed by international research on the usefulness of this classification system for guiding provision and simultaneously it feeds back into this body of knowledge, by bridging the gap between policy ideology and implementation. The main argument is that although the literature on SMART targets is widely known and regarded, professionals still feel they do not have the skills and supporting resources to develop good quality targets [14].

The Special Educational Needs and Disability policy in England and the potential of the International Classification of Functioning Disability and Health to support service provision 
In England there is a new policy for special education needs and disability provision - the Children and Families Act 2014 - which is accompanied by the Special Education Needs and Disability Code of Practice $[4,18]$. The two policies define a set of changes introduced in the system which have been systematically and critically analysed [12, 13, 17], and include: enhanced emphasis on multi-agency working to achieve an integrated, holistic assessment of the child or young person; the definition of a wider age range for the provision of special education services (now from birth to 25 years of age); a child-centred approach, in which the voices of the children and families themselves should be taken into account; an increased focus on child participation, quality of life in adulthood and removal of barriers to learning; and lastly, the replacement of the previous statements of Special Education Needs with Education Health and Care plans, as a result of a more collaborative and holistic assessment process. The Statements of special education needs were the documents that preceded Education health and Care plans in setting out the child's main needs and ideal supports. While the former were based mostly on diagnosis, the latter are not diagnosis-bound and they should focus on providing a good picture of the child's participation [4]. The government has set the deadline of April 2018 for all Statements to be converted into Education Health and Care plans [19]. However, this process has been markedly slow. In June 2016, only $29 \%$ had been converted [20], and between January 2016 and January 2017 only $32.7 \%$ conversions

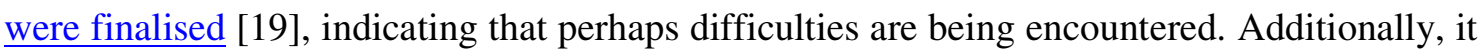
has been demonstrated that the quality of the newly developed Education Health and Care plans is questionable [21]. In this context, the new policy has been the object of various critiques, from all stakeholders and experts in the field, for not being clear enough in regard to its implementation.

It has been argued that the International Classification of Functioning Disability the Health (from hereon designated ICF) could support the development of higher quality Education 
health and Care plans, as its main principles are closely aligned with the principles of the Children and Families Act 2014, for example, that the descriptions of the child's functioning should not be based on diagnosis, but instead should provide a holistic picture of the child in all areas of life, and that multi-agency working is necessary to achieve holistic plans, therefore requiring a common language across professional areas [12, 17]. The ICF framework has long been recognised as the gold standard for describing disability in this manner and constitutes a common language for special education and disability across disciplines and social contexts $[15,16]$. Part of the 'family of classifications' developed by the World Health Organisation, it has been endorsed by all member countries as the gold standard taxonomy to describe disability for its unique characteristics of facilitating in-depth and individualised functioning profiles, which are also holistic, biopsychosocial and independent of diagnosis [22]. The potential of the ICF Classification as a supporting tool to develop rehabilitation targets for children with disabilities has been described in the literature $[23,24]$. The challenges of using this taxonomy have also been recognised extensively, namely the need to have some level of training and familiarisation with it before it can be adequately used ${ }_{2}$ especially within a multi-disciplinary team, in which each member has a very unique level of expertise [25]. Despite these widely acknowledged challenges, the ICF remains the main systematic international and evidence-based classification system of functioning and disability, enabling the description of functioning characteristics across all areas of life - from Body Functions and Structures and Activities and Participation dimensions, to Environmental Factors - that interact with and influence each other to result in one unique functioning profile $[15,16]$. For this reason, the ICF framework questions the medical model of disability and moves beyond the alternative proposed by the social model of disability. Through the ICF taxonomy, understanding disability from a functional and biopsychosocial perspective has been made practical as it enables a common language across 
professionals and contexts [26]; this common language can be adopted in day-to-day practice, with the adequate training in place.

The ICF has been introduced by law or by central disability services in many countries in which joint provision is required for supporting children with special education needs and disabilities. This is the case in Japan [27], Switzerland [28], Portugal [29], Italy [30] and most recently Germany [31], to name a few. Different countries have dealt with the need for training on the ICF in different ways but, overall, training has been provided to professionals through in-service continuous professional development, training at undergraduate and postgraduate level to facilitate qualifications that include some level of knowledge of the ICF framework and taxonomy and lastly, through government-funded initiatives.

In England, the ICF has been mentioned as a framework that is very closely aligned with the ideology of the recently introduced Children and Families Act 2014, and as a system with potential to help overcome some of the challenges observed in relation to the implementation of the new policy for special education needs and disability provision (e.g. $[12,13,17]$ ). However, the actual use of the ICF taxonomy in service provision and rehabilitation is limited and it is restricted to very few examples in the health sector, e.g. [32], thus not meeting the requirement for holistic assessment and intervention that the actual Children and

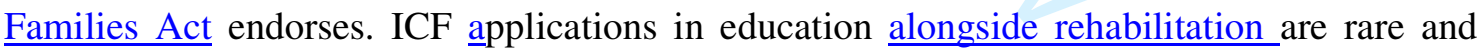
deserve further attention, given the goodness of fit between the this classification system and the English policy. One of the best examples of the goodness of fit between the ICF and the new special education needs and disability policy in England is the clearly specified requirement in the Code of Practice 2014 that the targets written for children (which comprise an entire section of the Education Health and Care plans) should be SMART. The acronym SMART is currently very popular in education but it has been adopted in a variety of settings across the social sciences, with slightly different variations of criteria terms; a large body of 
literature refers to SMART criteria as standing for Specific [6, 7]; Measurable [8], Actionoriented [9], Relevant [6, 7] and Time-framed [8]. The latter is the definition we use in this paper. Although the ICF was not developed with the specific purpose of facilitating goalsetting, it has been used successfully in this way [23, 24]. It can support the development of targets that are: specific -it constitutes an exhaustive taxonomy of activities, forms of participation, body functions, body structures and environmental issues; measurable -by providing a universal qualifier scale it reminds the user that identifying the functioning problem or the functioning area to target is not enough, and the magnitude of the problem observed in that area should also be documented with a clear measure for attainment decided; action-oriented -the ICF is, to date ${ }_{2}$ the only participation-focused international taxonomy; relevant -the level of detail within the ICF supports the differentiation between children who might have the same diagnosis but present slightly different functioning features, so the selection of the most important functioning features to describe each child has the potential to make outcomes more relevant; time-framed - the ICF is organised following a developmental hierarchy which underlines the importance of chronology in planning achievable targets.

The purpose of this paper is to report the results of a one-day training session on the ICF framework and classification system that was delivered in England for professionals working with children with special education needs and disabilities in three Greater London Local Authorities. The overall aim of this session was to increase awareness on the utility of the ICF framework for service provision in the current English policy context. In this study, our specific aims were to gauge the participants' views on the utility of the ICF for SEND provision in light of the new policy, and to measure the impact of the ICF training session on the quality of the targets written by the participants before and after the training, using the SMART criteria as quality indicators. 


\section{Method}

\section{Design and participants}

This study follows a pre- and post-test intervention design. The intervention is a training session on the ICF, delivered to professionals working with children with special education needs and disabilities and involved in the Education Health and Care writing process. Professionals from a variety of backgrounds within three Greater London local authorities were invited to attend a training session on the ICF system and its application as a supporting tool to write targets for children with special education needs and disabilities. These professionals had collaborated with the research team in various previous studies, though had never received any form of training or feedback from the research team on how to design better targets for children or higher quality Education Health and Care plans.

The first 25 participants that booked a ticket and met the criteria of working with children with disabilities and involved in writing Education Health and Care plans, were offered a place in the training. These included five Educational Psychologists, eight Special Educational Needs Coordinators, seven special education specialists from local authorities, three special education teachers and two speech therapists with local authority work experience. These are typical professional roles in the special education needs and disability support system in England. Local Authorities are sub-regions in charge of the provision of social, educational and health services for the community within their boundaries. Each local authority has a team of Educational psychologists who work in partnership with schools in the same geographical area. Each school has a Special Needs Coordinator, who is specially trained in, and responsible for, the provision of support services, and undertakes considerable leadership within this provision. Every local authority has a number of $\underline{\text { Special Needs }}$ 
Coordinators and specialists. The provision often include the ad-hoc intervention of speech and occupational therapists.

\section{Training Content and Approach}

The training session was six hours long and its main purpose was to raise awareness about the ICF and its potential to support service provision for children with special education needs and disability in three main ways: as a new way of conceptualizing disability (which, in this context should be understood as a multi-dimensional, biopsychosocial construct, independent of diagnosis); as a tool for discussions in multi-disciplinary teams and multi-agency working; and lastly, as a supporting tool to develop higher quality targets for children with special education needs and disabilities. The following learning outcomes were defined for the training session: participants will gain familiarity with the ICF as a classification system; participants will gain familiarity with the ICF as a framework to conceive disability, as well as with the history and purpose of its development; participants will be able to critically reflect on the usefulness of the ICF in the English socio-political context; and participants will be able to use the ICF system to perform simple coding and to write higher quality targets for children with disabilities.

The content of the session included an introductory part that explored in detail the rationale of the ICF and a brief history of its development. After this, an exploration of the coding system itself was undertaken: here, the structure of the taxonomy, the significance of the codes contained in it and how to find a specific dimension of functioning within the manual were the main topics covered. Lastly, various case studies were presented - narratives describing children with some form of special education need or disability; in small multidisciplinary groups, the participants were invited to find the codes/dimensions in the ICF that would better describe the child in consideration. 
The two instructors, who were both trained and experienced instructors on the ICF classification system, supervised, monitored and facilitated the discussions, providing input when necessary. The format of the training session was decided based on previous research providing evidence that instructor-led methodologies are the most efficient to increase knowledge on the ICF coding system itself [33], and on publications by the World Health Organistion which suggest training should be based on case-study reflection $[15,16,34]$.

All participants were given access to the ICF manual on-site, either through printed copies or online copies which are available to the public.

\section{Measures and procedure}

Before the training session, participants were asked to bring to the session one anonymised $\underline{\text { Education Health and Care plan of a child that they were very familiar with. This was an }}$ important criterion to ensure that the participatns would be in a position to write relevant holistic and individualised targets. The targets for the children included in these anonymised plans were regarded as pre-test measures of the effectiveness of the training.

Additionally, as part of examining the effectiveness of the training session in promoting the defined learning outcomes, specific forms were developed for which participants were invited to focus on the needs description section of the plan, as well as on the targets. Here, participants were asked to discuss and record their thoughts in relation to the extent to which the needs description could be improved; the extent to which the ICF could help to improve that section; and the extent to which the targets could be improved. The remaining item on the form invited the participants to write one new target using the ICF as a supporting tool to develop targets that are more specific, more measurable, action-oriented, relevant and timeframed (SMART); this served as a post-test measure of the effectiveness of the training session. The forms were filled in at the end of the training. The quality of the targets was 
rated independently by two experts in SEND in relation to each SMART criterion and the proportion of agreement between the two experts was calculated and used to decide upon the overall quality improvement of target writing.

At the end of the session, participants were also invited to fill in an evaluation questionnaire regarding the quality of the training. This was a paper and pencil questionnaire which took the participants five minutes to complete, and it included a mix of rating-scale questions and open-ended questions to gauge their views on the format and content of the training.

\section{Data Analysis}

Data resulting from the forms in which participants described their views on the needs and targets sections of the plans were analysed through systematic content analysis. Following an adaptation of procedures recommended in the literature for linking content with the ICF [35, 36], and similarly to procedures previously adopted in other studies [e.g.37-39], meaning units were extracted from the qualitative answers given in the forms regarding the items: quality of the needs description of the EHC plan under analysis, how the ICF could help improve the needs section and quality of the targets of the EHC plan under analysis. These meaningful units were identified jointly by the two researchers with similar expertise in the using the ICF system and framework. Following the identification of meaningful units, the two researchers independently clustered the meaningful units into common themes/categories. The percentage of agreement in assigning meaningful units to the themes was computed. Lastly, two independent experts on Special Education Needs and Disabilities were asked to rate each pair of targets according to which of the pair is more Specific, Measurable, Action-oriented, Relevant and Time-framed. Inter-rater agreement level was calculated with Cohen's Kappa and, where disagreement occurred, the final decisions were made by a third expert with similar background and experience. 


\section{Results \\ Participants' views on the descriptions of needs included in the EHC plans}

The participants' views on the descriptions of needs included in the EHC plans were gathered through forms designed to record their opinion on this. Participants wrote down their qualitative feedback in the respective area. Content analysis with meaningful unit identification and matching with main themes was conducted independently by two main researchers. The two researchers agreed on $97.2 \%$ of the matching between meaningful units and themes (78 of 81 meaningful units).

The majority of participants thought that the description of needs written before training could be improved (20 participants said yes and five did not respond to this question). Amongst the participants' responses in relation to how the needs' section could be improved the final agreed number of meaningful units to be analysed was 39. The most frequently mentioned problem was the lack of individualisation and specificity in the descriptions of the child and vague statements $(\mathrm{N}=28)$. Other issues pointed out by the participants were: language that is too technical $(\mathrm{N}=2)$, writing that is unclear $(\mathrm{N}=1)$, the impact of difficulties not being documented $(\mathrm{N}=2)$, duplicated information $(\mathrm{N}=3)$ the lack of information about the child's environment $(\mathrm{N}=1)$, and the lack of supporting evidence $(\mathrm{N}=2)$. Table 1 provides quotations as examples for each theme.

Amongst the participants' responses in relation to how the ICF could help improve the needs section, the most frequently mentioned advantage of the ICF in supporting the description of needs was its usefulness in reducing the vagueness of the statements $(\mathrm{N}=14)$, thus making them more specific (which has been pointed out before as the most problematic issue in the description of needs); this was followed by its capacity to support hypothetical thinking in 
developing targets for children, or in other words, of functioning as a problem-solving tool $(\mathrm{N}=8)$; Other frequently mentioned advantages included the ability to help organise information in writing $(\mathrm{N}=10)$, use of less technical language $(\mathrm{N}=3)$, serving as a common language $(\mathrm{N}=4)$ and the possibility of describing children's abilities/positive aspects of functioning $(\mathrm{N}=1)$. Two participants were of the opinion that the ICF does not have the capacity to improve the process of writing needs descriptions. Examples of quotations extracted from the evaluation forms and matched with the themes described above are also included in Table 1.

[Insert around here Table 1: Examples of quotes matching themes found in the participants' evaluation of needs sections in anonymised Education Health and Care plans]

\section{Participants' views on the targets included in the EHC plans}

Seventeen of the 25 participants reported that the outcomes needed to be improved. The remaining participants did not provide a response to this question. Seventeen meaningful units were arranged in themes with two independent coders agreeing on all meaningful units identified. Table 2 provides a summary of the justifications given by the participants as to why the outcomes need improvement: the units mostly match various aspects of the SMART criteria, or they actually state that the outcomes could be 'SMARTer'; one participant mentioned the use of language that is too technical and absence of a clear link to the child's needs.

[Insert around here Table 2: Examples of quotes in response to the item: Why do you think the targets' section could be improved?] 


\section{Comparison of targets before and after the 'taster' session}

Table 3 shows the targets that were analysed and written before and after the training session by each participant, along with the agreed ratings according to SMART criteria. Sixteen participants had pairs of targets written before and after the session. Both independent experts have been working and researching in the field of SEND provision for more than 20 years and are educated at Doctoral level in this field. Agreement was reached for $76 \%$ of the 80 items (16 items per SMART criterion); Cohen's kappa level of agreement was .52, which is considered moderate [40]. For this reason a third independent judge was called upon for decision-making on items disagreed.

Overall, the majority of the targets developed by the participants after the training session improved in quality against all SMART criteria, with the exception of the time-frame criterion, with only 6 targets out of 16 rated as having higher quality. The targets improved mainly in terms of relevance, with 15 out of 16 outcomes rated higher after the training session. Thirteen out of 16 targets were rated as more specific, 10 out of 16 were rated as more Action-oriented and 8 out were rated as more measurable.

[Insert around here Table 3. Children's targets before and after the ICF training session and quality rating against SMART criteria]

\section{Participants' views on the training session}

Twenty-three participants replied to the evaluation forms. Twenty-one out of 23 participants had never heard about the ICF before, but after the training session, 19 participants considered there to be a clear match between the ICF and the new special education needs and disability policy in England. When asked about which aspects they believed the ICF could help improve in relation to the implementation of the new policy, the most frequently 
mentioned were: supporting multi-agency work $(\mathrm{N}=19)$; the development of more individualised descriptions of functioning $(\mathrm{N}=18)$; developing holistic Education Health and Care plans $(\mathrm{N}=17)$; and developing plans with less technical jargon $(\mathrm{N}=14)$. Twenty-one out of 23 participants would recommend this training session to other colleagues working in

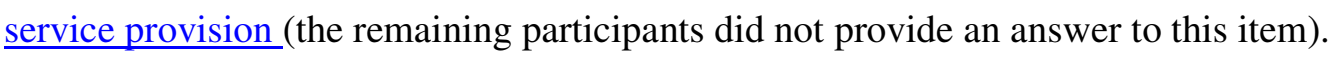

\section{Discussion}

This study aimed to report the results of a one-day training session on the ICF framework and classification system that was delivered in England for professionals working with children with special education needs and disabilities, to support the development of higher quality Education Health and Care plans, and specifically, higher quality targets for children. Overall, the results of this study provided some indication that professionals are able to identify quality issues within the plans currently being developed for children; simultaneously, and although ICF applications in service provision are rare, professionals seem receptive to an internationally recognised model and classification system that seems to have clear potential to help overcoming these issues. There seems to be professional willingness to bridge the gap between policy and implementation [11] and adapt evidencebased international models, if they help to improve our system. For the professionals, it looks like 'no policy is an island' and that there are lessons to be learned from the international research on special education needs and disability.

Regarding the participants' views on the usefulness of the ICF to support the development of Education Health and Care plans, most agreed that the plans could be improved, in particular by reducing the vagueness of the statements included in the 'description of needs' section of the plans; here, the ICF was regarded by most participants as a tool with considerable potential to support the development of more specific statements. When asked about the 
quality of the targets, most participants referred to aspects related to the need for SMARTer targets, in particular that they need to be a lot more specific and relevant. Research on the quality of the actual content of the plans is scarce; however our results seem to match recent findings from a systematic analysis of the quality of the plans, showing questionable quality standards including, for example, inadequate portrayal of the views of the children and families themselves, a very high number of vague statements and low level of individualisation [21]. This has been attributed to the absence of evidence-based systems or guidelines to support professionals in the development and implementation of the recently introduced Education Health and Care plans, thus suggesting the existence of a gap between the ideology conveyed in the English policy and its practical implementation $[12,21]$. The views of the participants in this study regarding the quality of the_plans they analysed in the training session is a reflection of this gap. However, most professionals agreed that the ICF has the potential to help overcome these issues and could provide the necessary framework to guide higher quality practices.

Regarding the comparison of targets written before and after the training, we have seen an improvement in the majority of the outcomes written after the training session, especially in the extent to which they are action-oriented, specific and relevant. For example, participant number 2 improved the written target against all SMART criteria, by specifying how the child will develop his listening skills (through assistive technology) and in which daily settings/opportunities (group situations). Here, the structure of the ICF, which includes a component on environmental factors that restrict or facilitate participation, where a detailed list of these factors is presented, has helped the participant to identify 'assistive technology' (coded in the ICF as e1251 - Assistive products and technology for communication) as a factor that should be added to this target. Similarly, the ICF chapter on 'supports and relationships' has helped the participant to identify the daily routine moments when he/she 
would like to work on this target - 'group situations', which promote peer relationships (coded in the ICF manual under $d 7504$ - Informal relationships with peers). Participant number 12 improved against all SMART criteria; the rather vague statement 'improve her independent working skills' was replaced with a specific indicator of independence - making choices between two options; this makes the target more specific and measurable, but also more relevant as its context is made more concrete. It was by looking at the ICF's extensive level of detail and focusing on finding potential indicators of independence and autonomy, that the participant identified the code $\mathrm{d} 177$ - Making decisions, in chapter 1 of the Activities and Participation component, which related to Learning and Applying Knowledge. The taxonomy structure of the ICF provides a guideline, or a 'reminder' of skills that can be mentioned and used as points of reference in writing targets for children. The reliability level obtained as a result of inter-rater agreement is similar to that obtained in similar previous studies. For example, in the study by Nijhuis and colleagues [24] on the role of the ICF in supporting goal-setting in Dutch paediatric rehabilitation facilities, Cohen's Kappa reliability checks between raters ranged from 'fair' to 'good'.

Regarding the participants' views on the usefulness of the training, most of the participants, not having heard about the ICF before, now recognise its value in multiple ways, and in connection to the English special education needs and disability policy. It is interesting to see that most participants mentioned the ICF's added value as a tool to support multi-agency working, after having had the experience of using it to write new targets for children in small multidisciplinary groups; this attests that the ICF can facilitate a positive multi-agency working experience and be seen by professionals as a helpful tool to design higher quality Education health and Care plans. It also shows that the circumstances in England are not atypical: despite a unique local policy on special education needs and disability provision, this policy would benefit from including an internationally recommended framework such as 
the ICF; 'no policy is an island' and we should study the possibilities of integrating good practice observed in other countries into our own local policy.

Some limitations of the study should also be mentioned alongside recommendations for future research. The study reports one single training session on the ICF, potentially the first conducted in England, to our knowledge. Thus, it provides an indication of the general lack of awareness of the taxonomy and also an indication of how it can be well-received by professionals if it was to be considered at policy level. However, more widespread training would be necessary to fully understand the implications of introducing the ICF in service provision. Future research should invest on other models of ICF training (including models embedded in context and involving a multi-disciplinary team), and on tracking the use of the ICF by the professionals trained in a long-term follow-up; this would provide more definite evidence of the usefulness of this system for education planning and provision. Another limitation is that although the improvement in the targets developed by the participants in this study demonstrates the potential of the ICF to help improve quality, the resulting targets could still be further improved when considering international good practices for special $\underline{\text { education needs and disability service provision. Moreover, even though the professionals }}$ knew the children for whom the outcomes were being written in the session, this was still an exercise removed from its context and results should, therefore, be interpreted as an indication, not as a definite conclusion. Additionally, the ICF training has not helped improve the criterion time-frame in the analysed targets, which still lack quality at this level. This is, however, an indication that higher quality training might be needed for professionals in England, regardless of the introduction of the ICF. Further research initiatives should focus on larger scale studies on the impact of widespread ICF training on the quality of service provision at various levels. 


\section{Conclusion}

Nationally, there has been some debate on the challenges of the special education needs and disability policy and even less consideration has been given to possible alternative models that have the potential to retain the ideological assets of the English policy, while simultaneously helping to overcome the gap in ideology and implementation. Our study has provided evidence that the ICF has the potential to become such an alternative model and we argue, based on this evidence, that perhaps we need to move beyond the 'indoor' criticism of the local policy and open our horizons to international policy on special education needs and disability service provision. For 18 years the ICF has been considered the international gold standard for disability classification by the World Health Organisation. Member countries (including the United Kingdom) have ratified the commitment to promote its use at local level [22]. However, this study shows there is very little local awareness of the classification and of its potential at professional level; at policy level, even though the principles (of multiagency working, interdisciplinary work and holistic interventions) reflect internationally recognised good practices $[41,42]$, in practice we are not opening doors to frameworks that have shown efficacy beyond our borders. The results of our study suggest that 'no policy is an island', and there are reasons to invest in considering international lessons learned to help improve our SEND policy and provision. One way of doing this is to start the debate on the role of the ICF in promoting good practices, at national level. There can be value for money in adopting the ICF framework at this stage in England, when most necessary research to introduce the system into provision services has already been done internationally: forms of training are available in various formats and ICF-based checklists, measures and guidelines have been widely distributed $[43,44]$. Only political willingness seems to be necessary for bridging the gap beyond 'the island'. 


\section{References}

1. Mitchell D, Morton M, Hornby G. Review of the literature on individual education plans. New Zealand: Ministry of Education; 2010.

2. European Agency for Development in Special Needs Education [Internet]. Assessment resource guide. 2010. Available from: http://www.europeanagency.org/agencyprojects/assessment-resource-guide R

3. Björck-Åkesson E, Wilder J, Granlund M, Pless M, Simeonsson R, Adolfsson M, Almqvist L, Augustine L, Klang N, Lillvist A. The international classification of functioning, disability and health and the version for children and youth as a tool in child habilitation/early childhood intervention-feasibility and usefulness as a common language and frame of reference for practice. Disabil Rehabil. 2010;32(sup1):S138.

4. Legislation.gov.uk. [Internet]. Children and Families Act 2014. [cited11 Jan. 2015]. Available from: http://www.legislation.gov.uk/ukpga/2014/6/contents/enacted

5. Millward A, Baynes A, Dyson A, Riddell S, Banks P, Kane J, Wilson A. Individualised educational programmes. part I: A literature review. J. of Res in Special Educ Needs. $2002 ; 2(3)$

6. Siegert RJ, Taylor WJ. Theoretical aspects of goal-setting and motivation in rehabilitation. Disabil Rehabil. 2004;26(1):1-8.

7. Jung LA. Writing SMART objectives and strategies that fit the ROUTINE. Teach Exceptional Child. 2007;39(4):54-8.

8. Conzemius, A, O'Neill, J. The power of SMART goals: Using goals to improve student learning. Mission BC: Solution Tree Press; 2009.

9. Piskurich, GM. Rapid instructional design: Learning ID fast and right. Hoboken, New Jersey: Wiley; 2015. 
10. Dalen HE, Nyquist A, Saebu M, Roe C, Bautz-Holter E. Implementation of ICF in goal setting in rehabilitation of children with chronic disabilities at Beitostolen Healthsports Centre. Disability and rehabilitation. 2013 Feb 1;35(3):198-205.

11. Nguyen L, Mesterman R, Gorter JW. Development of an inventory of goals using the international classification of functioning, disability and health in a population of nonambulatory children and adolescents with cerebral palsy treated with botulinum toxin A. BMC pediatr. 2018;18(1):1.

12. Castro S, Palikara O. Mind the Gap: The New Special Educational Needs and Disability Legislation in England. Front Educ. 2016;1(4):1-9.

13. Castro S, Palikara O. The education health and care planning process in England. In: Castro S, Palikara O, editors. An Emerging Approach for Education and Care: Implementing a Worldwide Classification of Functioning and Disability. Abingdon: Routledge; 2017. p. 3952.

14. Palikara O, Castro S, Gaona C, Eirinaki V. Professionals' views on new policy for special educational needs in England: ideology versus implementation. Eur J of Special Educ Needs. 2018;18:1-5.

15. World Health Organisation (WHO). International Classification of Functioning, Disability and Health. Geneva: WHO; 2001.

16. World Health Organisation (WHO). International Classification of Functioning, Disability and Health-Child and Youth Version. Geneva: WHO; 2007.

17. Norwich B. Conceptualising special educational needs using a bio-psycho-social model in England: the prospects and challenges of using the International Classification of Functioning framework. Front Educ. 2016;1(5). 
18. Department for Education. SEN and Disability Code of Practice: Statutory Guidance for Organisations Who Work with and Support Children and Young People with Special Educational Needs and Disabilities. London: DfE; 2014

19. Department for Education. Special Educational Needs and Disability (SEND). London: DfE; 2017

20. Department for Education. Statements of SEN and EHC plans: England, 2016. London: DfE; 2016

21. Palikara O, Castro S, Gaona C, Eirinaki V. Capturing the voices of children in the Education Health and Care plans: are we there yet?. Front Educ. Forthcoming Year.

22. Stucki G, Kostanjsek N, Cieza A. The International Classification of Functioning, Disability and Health: A Tool to Classify and Measure Functioning In: Handbook of Disease Burdens and Quality of Life Measures. Springer; 2010. p. 1-34.

23. McLeod S, Bleile K. The ICF: A framework for setting goals for children with speech impairment. Child Lang Teach Ther. 2004;20(3):199-219.

24. Nijhuis BJ, Reinders-Messelink HA, de Blécourt AC, Boonstra AM, Calamé EH, Groothoff JW, Nakken H, Postema K. Goal setting in dutch paediatric rehabilitation. are the needs and principal problems of children with cerebral palsy integrated into their rehabilitation goals? Clin Rehabil. 2008;22(4):348-63.

25. Eldar R, Marincek C, Kullmann L. Need for rehabilitation teamwork training in Europe. Croat Med J. 2008;49(3):352-7.

26. Simeonsson RJ. Defining and classifying disability in children. Disability in America. Washington: National Academic Press; 2006. p. 67-86.

27. Tokunaga A, Tanaka K, Sakai Y. The use of the ICF-CY in special needs education in japan. In: Castro S, Palikara O, editors. An Emerging Approach for Education and Care: 
Implementing a Worldwide Classification of Functioning and Disability. Abingdon:

Routledge; 2017. p. 71-84.

28. Hollenweger J. Development of an ICF-based eligibility procedure for education in Switzerland. In: BMC Public Health. BioMed Central; 2011;11(4):S7.

29. Sanches-Ferreira M, Simeonsson RJ, Silveira-Maia M, Alves S, Tavares A, Pinheiro S. Portugal's special education law: Implementing the international classification of functioning, disability and health in policy and practice. Disabil Rehabil. 2013;35(10):868-73.

30. Leonardi M, Bickenbach J, Raggi A, Sala M, Guzzon P, Valsecchi MR, Fusaro G, Russo E, Francescutti C, Nocentini U. Training on the international classification of functioning, disability and health (ICF): The ICF-DIN basic and the ICF-DIN advanced course developed by the disability italian network. $\mathrm{J}$ of headache and pain. 2005;6(3):159-64.

31. Pretis M. "Let us be prepared, but wait and see" the use of ICF-CY in early childhood intervention and paediatric social care in Germany and neighbouring countries. In: Castro S, Palikara O, editors. An Emerging Approach for Education and Care: Implementing a Worldwide Classification of Functioning and Disability. Abingdon: Routledge; 2017. p. 165177.

32. Lawlor K, Mihaylov S, Welsh B, Jarvis S, Colver A. A qualitative study of the physical, social and attitudinal environments influencing the participation of children with cerebral palsy in northeast England. Pediatr Rehabil. 2006;9(3):219-28.

33. Reed GM, Dilfer K, Bufka LF, Scherer MJ, Kotz P, Tshivhase M, Stark SL. Three model curricula for teaching clinicians to use the ICF. Disabil Rehabil. 2008;30(12-13):927-41.

34. World Health Organisation (WHO). Reducing Risks, Promoting Healthy Life. Geneva: WHO; 2002.

35. Stucki G. ICF linking rules: An update based on lessons learned. J Rehabil Med. 2005;37(37):212-8. 
36. Cieza A, Fayed N, Bickenbach J, Prodinger B. Refinements of the ICF linking rules to strengthen their potential for establishing comparability of health information. Disabil Rehabil. 2016:1-10.

37. Castro S, Ferreira T, Dababnah S, Pinto AI. Linking autism measures with the ICF-CY: Functionality beyond the borders of diagnosis and interrater agreement issues. Dev Neurorehabilit. 2013;16(5):321-31.

38. Castro S, Pinto A, Simeonsson RJ. Content analysis of portuguese individualized education programmes for young children with autism using the ICF-CY framework. Eur Early Child Educ Res J. 2014;22(1):91-104.

39. Ibragimova NK, Pless M, Adolfsson M, Granlund M, Björck-Åkesson E. Using content analysis to link texts on assessment and intervention to the international classification of functioning, disability and health-version for children and youth (ICF-CY). J Rehabil Med. $2011 ; 43(8): 728-33$.

40. Landis JR, Koch GG. An application of hierarchical kappa-type statistics in the assessment of majority agreement among multiple observers. Biometrics. 1977:363-74.

41. Sandall, S, McLean, ME, Smith, BJ. DEC recommended practices in early intervention/early childhood special education. Washington, DC: ERIC; 2000.

42. Watson D, Townsley R, Abbott D. Exploring multi-agency working in services to disabled children with complex healthcare needs and their families. J Clin Nurs. 2002;11(3):367-75.

43. Cieza A, Ewert T, Ustun TB, Chatterji S, Kostanjsek N, Stucki G. Development of ICF core sets for patients with chronic conditions. J Rehabil Med. 2004(44):9-11.

44. Morris C, Kurinczuk JJ, Fitzpatrick R. Child or family assessed measures of activity performance and participation for children with cerebral palsy: A structured review. Child: care, health and dev. 2005;31(4):397-407. 
Table 1. Examples of quotes matching themes found in the participants' evaluation of needs sections in anonymised Education Health and Care plans

\begin{tabular}{|c|c|c|}
\hline \multicolumn{3}{|c|}{ Item: How does the needs section of the EHC plan require improvements? } \\
\hline Theme & Quote & $\begin{array}{l}\text { Participant } \\
\text { Number }\end{array}$ \\
\hline $\begin{array}{l}\text { Lack of individualisation and } \\
\text { specificity and vague } \\
\text { statements }(\mathrm{N}=28)\end{array}$ & $\begin{array}{l}\text { Some of the descriptors and terms used were too } \\
\text { broad and required further clarification and context. } \\
\text { The description is very much at the skill level for } \\
\text { individual (...) writing tasks; does not provide any } \\
\text { general sense of how he interacts with reading and } \\
\text { writing }\end{array}$ & 17 \\
\hline Writing that is unclear $(\mathrm{N}=1)$ & some sentences do not make sense & 5 \\
\hline $\begin{array}{l}\text { Impact of difficulties not } \\
\text { documented }(\mathrm{N}=2)\end{array}$ & $\begin{array}{l}\text { focus more on each difficulty / area of need and how } \\
\text { it impacts on the child's everyday life and learning }\end{array}$ & 7 \\
\hline Duplicated information $(\mathrm{N}=3)$ & $\begin{array}{l}\text { some information duplicated in different sections, e.g } \\
\text { about making mistakes - in 'cognition and learning } \\
\text { and in 'social, emotional \& mental health' }\end{array}$ & 5 \\
\hline $\begin{array}{l}\text { Lack of information about } \\
\text { environment }(\mathrm{N}=1)\end{array}$ & More descriptions of support environment & 1 \\
\hline $\begin{array}{l}\text { Lack of supporting evidence } \\
(\mathrm{N}=2)\end{array}$ & some (...) assertions without evidence & 18 \\
\hline $\begin{array}{l}\text { Language that is too technical } \\
(\mathrm{N}=2)\end{array}$ & inclusion of too technical language & 8 \\
\hline \multicolumn{3}{|c|}{ Item: How do you think the use of the ICF could help improve the needs section? } \\
\hline Theme & Quote & $\begin{array}{l}\text { Participant } \\
\text { Number }\end{array}$ \\
\hline $\begin{array}{l}\text { Usefulness in reducing the } \\
\text { vagueness of the statements } \\
(\mathrm{N}=14)\end{array}$ & $\begin{array}{l}\text { I think the ICF breaks areas of need down so much } \\
\text { more that you can get a better picture of needs in } \\
\text { each area. } \\
\text { It serves as a reminder to be more specific and } \\
\text { prompts discussion about what is meant }\end{array}$ & 4 \\
\hline $\begin{array}{l}\text { Functioning as a problem- } \\
\text { solving tool }(\mathrm{N}=8)\end{array}$ & $\begin{array}{l}\text { use of multiple codes to pair up so that reason for } \\
\text { presenting need can also be addressed; }\end{array}$ & 2 \\
\hline & makes you pinpoint the reason for certain behaviours & 9 \\
\hline $\begin{array}{l}\text { Helps organising information } \\
\text { in writing }(\mathrm{N}=10)\end{array}$ & prompts phrasing / terminology & 8 \\
\hline & $\begin{array}{l}\text { to help organise description of needs into sections - } \\
\text { this should make it easier to locate information }\end{array}$ & 10 \\
\hline $\begin{array}{l}\text { Use of less technical language } \\
(\mathrm{N}=3)\end{array}$ & $\begin{array}{l}\text { much clearer, easier to put in simple language, } \\
\text { without jargon and write a lot less }\end{array}$ & 9 \\
\hline $\begin{array}{l}\text { The possibility of describing } \\
\text { children's abilities/positive } \\
\text { aspects of functioning }(\mathrm{N}=1)\end{array}$ & $\begin{array}{l}\text { useful to identify initial stage of learning achieved as } \\
.0 \text { and severity of need where expected level not } \\
\text { achieved. Represents positives as well as } \\
\text { developmental needs. }\end{array}$ & 2 \\
\hline $\begin{array}{l}\text { Serves as a common language } \\
(\mathrm{N}=4)\end{array}$ & $\begin{array}{l}\text { it can offer a narrative that consists of a common } \\
\text { language to simplify this section. }\end{array}$ & 20 \\
\hline ICF does not help $(\mathrm{N}=2)$ & I don't think the ICF would improve that much. & 6 \\
\hline
\end{tabular}


Table 2. Examples of quotes in response to the item: Why do you think the targets' section could be improved?

\begin{tabular}{|c|c|c|c|}
\hline Theme & Sub-Theme & Quote & $\begin{array}{l}\text { Participant } \\
\text { Number }\end{array}$ \\
\hline \multirow[t]{6}{*}{ Being SMART $(\mathrm{N}=17)$} & More measurable $(\mathrm{N}=3)$ & $\begin{array}{l}\text { require consistent use of appropriate } \\
\text { quantification }\end{array}$ & 2 \\
\hline & Not relevant $(\mathrm{N}=5)$ & $\begin{array}{l}\text { The outcomes are generally very aspirational } \\
\text { and not necessarily realistic/achievable. }\end{array}$ & 21 \\
\hline & & $\begin{array}{l}\text { There was not one outcome that was connected } \\
\text { to the child's needs }\end{array}$ & 16 \\
\hline & More specific $(\mathrm{N}=5)$ & $\begin{array}{l}\text { they need to be more specific, more related to } \\
\text { the individual child }\end{array}$ & 18 \\
\hline & Indicate timeline $(\mathrm{N}=2)$ & $\begin{array}{l}\text { indicate the timeline by which we expect the } \\
\text { child to achieve the target }\end{array}$ & 7 \\
\hline & Could be SMARTer $(\mathrm{N}=2)$ & the goals are not smart & 3 \\
\hline Use of language $(\mathrm{N}=1)$ & $\begin{array}{l}\text { Less technical language } \\
(\mathrm{N}=1)\end{array}$ & $\begin{array}{l}\text { I have reflected on phrases such as '50\%' and } \\
\text { realised they may not be meaningful to parents } \\
\text { and teachers. }\end{array}$ & 16 \\
\hline
\end{tabular}


Table 3. Children's targets before and after the ICF training session and quality rating against SMART criteria

\begin{tabular}{|c|c|c|c|c|c|c|c|}
\hline \multirow[t]{2}{*}{ Participant } & \multirow[t]{2}{*}{ Target 1} & \multirow[t]{2}{*}{ Target 2} & \multicolumn{5}{|c|}{$\begin{array}{c}\text { Improvement from time } 1 \text { to time } 2 \\
\text { after inter-rater agreement }\end{array}$} \\
\hline & & & Specificity & Measurability & $\begin{array}{l}\text { Action- } \\
\text { oriented }\end{array}$ & Relevant & $\begin{array}{l}\text { Time- } \\
\text { framed }\end{array}$ \\
\hline 4 & $\begin{array}{l}\text { Will be able to work at an appropriate developmental } \\
\text { level }\end{array}$ & $\begin{array}{l}\text { Will be able to express his needs and wishes, for } \\
\text { example by reaching to show his communication } \\
\text { device by request }\end{array}$ & $\sqrt{ }$ & $\sqrt{ }$ & $\sqrt{ }$ & $\sqrt{ }$ & $\mathrm{X}$ \\
\hline 9 & $\begin{array}{l}\text { Will be taking other people's feelings into } \\
\text { consideration before she reacts }\end{array}$ & $\begin{array}{l}\text { Will be able to regulate her emotions and impulses, } \\
\text { verbal aggression and physical aggression in } \\
\text { interaction with others in a contextually and } \\
\text { socially appropriate manner }\end{array}$ & $\mathrm{X}$ & $\mathrm{X}$ & $\mathrm{X}$ & $\checkmark$ & $\mathrm{X}$ \\
\hline 10 & $\begin{array}{l}\text { Will be able to access all areas of the national } \\
\text { curriculum at his own individual pace }\end{array}$ & $\begin{array}{l}\text { Will develop her understanding of complex spoken } \\
\text { messages so that she can follow simple instructions } \\
\text { given to the whole class with independence }\end{array}$ & $X$ & $X$ & $\checkmark$ & $\sqrt{ }$ & $\mathrm{X}$ \\
\hline 11 & $\begin{array}{l}\text { Will develop his receptive and expressive skills to a } \\
\text { level where he can follow simple verbal instructions } \\
\text { (initially two part) when supported with visual cues, } \\
\text { such as 'now' and 'next' or simple visual timetable }\end{array}$ & $\begin{array}{l}\text { By the end of year } 5, X \text { will be able to start, sustain } \\
\text { and end an interchange of thoughts and ideas } \\
\text { carried out by means of spoken language with one } \\
\text { or more persons }\end{array}$ & $\checkmark$ & $\checkmark$ & $X$ & $\mathrm{X}$ & $\checkmark$ \\
\hline 12 & $\begin{array}{l}\text { Will develop her attention and concentration skills so } \\
\text { that she can improve her independent working skills }\end{array}$ & $\begin{array}{l}\text { Will be able to make a choice when given two } \\
\text { options and then implement and evaluate the } \\
\text { effects of this choice through guided reflection } \\
\text { with an adult }\end{array}$ & $\sqrt{ }$ & $\checkmark$ & $\sqrt{ }$ & $\sqrt{ }$ & $\checkmark$ \\
\hline 13 & $\begin{array}{l}\text { Will build his receptive and language skills, } \\
\text { understand key concepts, time and activities and } \\
\text { follow adult-directed instructions }\end{array}$ & $\begin{array}{l}\text { Will be able to describe a picture by producing a } \\
\text { sentence using subject-verb-object structure (e.g. } \\
\text { the boy is kicking the ball) supported by colourful } \\
\text { semantics (intervention where parts of a sentence } \\
\text { are colour-coded) }\end{array}$ & $\sqrt{ }$ & $\checkmark$ & $\checkmark$ & $\checkmark$ & $\mathrm{X}$ \\
\hline 14 & $\begin{array}{l}\text { Will develop social communication skills and be } \\
\text { confident to speak in a variety of situations }\end{array}$ & $\begin{array}{l}\text { Will be able to initiate conversation with a peer in } \\
\text { each school day by the end of key stage } 2\end{array}$ & $\sqrt{ }$ & $\mathcal{I}$ & $\checkmark$ & $\checkmark$ & $\checkmark$ \\
\hline 15 & $\begin{array}{l}\text { Will develop his approach to learning so that he can } \\
\text { continue making progress }\end{array}$ & $\begin{array}{l}\text { Will improve her receptive and expressive } \\
\text { language skills using visual prompts like within- } \\
\text { task prompt sheets }\end{array}$ & $\sqrt{ }$ & $\mathrm{X}$ & $\sqrt{ }$ & $\checkmark$ & $\mathrm{X}$ \\
\hline 16 & $\begin{array}{l}\text { Will develop a more dynamic grasp to facilitate his } \\
\text { pencil control and writing stamina }\end{array}$ & $\begin{array}{l}\text { Will be able to converse with many peers and } \\
\text { adults by participating in a group interchange } \\
\text { during lesson starters until the lesson starter has } \\
\text { finished and to do this everyday }\end{array}$ & $\checkmark$ & $\checkmark$ & $\checkmark$ & $\checkmark$ & $\checkmark$ \\
\hline 17 & $\begin{array}{l}\text { Will develop his social skills to a level where he can } \\
\text { develop healthy social relationships }\end{array}$ & $\begin{array}{l}\text { Will be able to initiate and maintain and } \\
\text { interchange with a peer during a structured } \\
\text { classroom activity for } 10 \text { minutes on a daily basis }\end{array}$ & $\checkmark$ & $\checkmark$ & $\checkmark$ & $\checkmark$ & $\sqrt{ }$ \\
\hline
\end{tabular}



to support her independent learning

21 Will be able to follow instructions independently

Will be able to communicate his basic needs wishes and comments through use of short phrases/sentences and/or augmentative communication systems and will be able to follow familiar instructions and new information.

Will develop his social interaction skills so that he can form relationships and participate in school life Will develop his listening and attention skills to a level where he can carry out classroom instruction and complete a task independently

Will be able to interact with people in a contextually
Will participate in a group discussion for a short

period of time by responding to a contribution from someone else and staying in the topic

$\mathrm{G}$ will be able to develop an awareness of needing to go to the toilet and communicate this to adults

Will be able to produce words, phrases and longer

passages in spoken language with literal and

mplied meaning such as expressing a fact or telling a story

To sustain a conversation with another person and responding on the same topic for several exchanges The child will be able to follow instructions,

understand the work set in the classroom using assistive technology at all times ad participate fully in group situations

Will be able to interact with people in a

contextually and socially appropriate manner by showing consideration and esteem when appropriate or responding to the feelings of others

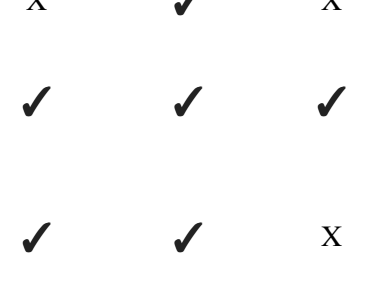


56

57

58

59 